\title{
Towards quasi - formal management of paratransit in informal transport dependent cities of Nigeria
}

\author{
Shittu, A.O \\ shittuabdulmajeed@yahoo.ca oraoshittu@abu.edu.ng \\ Department of Urban and Regional Planning, Faculty of Environmental Design, \\ Ahmadu Bello University, Zaria - Nigeria
}

\begin{abstract}
Most city authorities in paratransit dependent urban centres are inclined towards formalization of public transport operations, perceivably as a way of excluding informality and bringing sanity and control to the sector. Such city authorities do not seem to recognize the contribution of paratransit to the enhancement of mobility and accessibility, even when capacity to formalize or regulate public transportation is grossly lacking. Several failed attempts at radical transformation of paratransit in such environments are attested to within available literature. The situation is further compounded by derailments suffered from spirited resistance to radical transformation by thousands of operators in the sector. The manifest consequences include ineffective mobility, reduced productivity, unlevel playing field, underutilized formal transit, if any, and other forms of economic and social losses. Against this backdrop, a shift in thinking towards non radical techniques of supervising paratransit operations in paratransit dependent cities is suggested. Overt institutional control should begin to give way to covert participation and supervision. This is necessary because the paratransit sector have for decades proven to be a veritable mobility option in paratransit dependent cities. Hence, the real challenge is in finding ways of harnessing advantages and mitigating disadvantages inherent in paratransit operations. It is believed that by moving away from the problematic formalization and laissez - faire postures commonly adopted by authorities of paratransit dependent cities, quasi-formal management approaches may offer room for reasonable supervision to take effect.
\end{abstract}

Keywords: Formalization, paratransit operations, quasi-formal framework, urban mobility

\section{Introduction}

Challenges of formalization and laissez - faire regimes in paratransit dependent cities have been generating debate on how to effectively administer paratransit. For instance, formalization, as being implemented in South Africa [1], recognition by municipal authorities as in the case of Ghana and Kenya [2] and prohibition as was tried in Abuja - Nigeria [3], have led to varying outcomes. Formalization postures usually face operator resistance that sometimes results in social turmoil [1]. In partial regulation regimes, identifying what to regulate and what to leave in the hands of operators have continued to prove difficult for authorities. Recognition and laissez - faire on the other hand, is characterized by operator dominance, overcompetition, traffic issues and institutional helplessness [4].

The varying techniques and approaches employed in managing paratransit services such as franchising, territory definition, entry charges, vehicle and driver age restrictions, tenders, licensing and limitation of number of vehicles per operator, to mention a few, have interestingly shown recognizable traits that tend to determine outcome. Some of the characteristic traits, include but are not limited to; one, the one-off targeting of specific issues; two, the piecemeal nature of arrangements; three, the top to bottom approach and four, the presumption to control or hands off. Whereas considering paratransit services as needed service, with advantages that can be systematically harnessed while limiting undesirable manifestations might be an alternate posture.

Exploring this alternate posture is necessary considering that large cities of the developing world are according to [1] "natural breeding grounds for informal transport services. The absence of reliable "formal services usually leaves huge gaps to be filled". [5] also affirmed that an average of 80 per cent of urban residents in some cities of developing countries rely on public transportation, of which a large proportion is not formal transit services. For instance, over 90 percent of the public transport need of the capital city of Nigeria - Abuja is provided by informal private operators of minibuses [6]. In Kenya, 70 per cent of Nairobi's public transport requirement is handled by "matatus" [7]. Privately run express vans in Brazil maintain a large share of commute trips [8]. "Collectivos" and "Peseros" are known to service an increasing portion of public transport needs of Mexico [2]. More so, the important role informal transport plays in facilitating mobility, towards improving accessibility to employment, education, health and other urban services necessary for enhanced welfare [9, 10, 11] are other grounds to consider paratransit in whatever form - so long as it enables the mobility of people without private transport - as part of the solution in bridging urban mobility service gaps and not hastily 
condemned as problems. Apparently, the huge dependence on paratransit in some cities suggests that informal transport arrangements are and will continue to be relevant, at least into the foreseeable future.

The central task thus, is to device means of improving urban productivity for urban residents by catering for their mobility needs in an economically efficient and socially inclusive manner. Priority should then be on issues that would help sanitize the sector in paratransit dependent cities, as a way of enabling the sector to deliver desirable results. Among the pertinent requirements is the identification of opportunities in the informal public transport service domain. The argument thus is that paratransit regulation or formalization needs to be approached in a different manner, consistent with the need, peculiarities and institutional capacity of a paratransit dependent city. The continued emphasis on institutional control, or partial regulation and the much less effective "do nothing" approach from the judgmental perspective of modern ideology based intolerance where services provided by the sector are seen as illegal or illicit - needs to change. This research seeks to suggest a framework for a quasi - formal approach to paratransit management in informal transport dependent cities of Nigeria.

The approach adopted in this work involves drawing lessons from relevant literature as a way of identifying salient and pertinent issues in the ongoing debate on formalization of public transportation in developing nations. The pros and cons associated with the current policy stance towards formalization were identified as bases for suggesting an alternative framework for managing paratransit operations in paratransit dependent cities of Nigeria.

\section{Debate on Formalization and Regulation of Informal Transportation}

Over the years the general policy stance of governments on informal transport has been categorized by [2] to be from acceptance to prohibition, representing different degrees of regulatory stringency from lax to strict "Fig. 1". Other authors have chosen the "prohibit - ignore or regulate" continuum [8]. Another way of describing the range can be between the "compel - nurture" extremes. Every point along the spectrum has taxed city authorities to varying levels and has generated different responses from informal service providers.

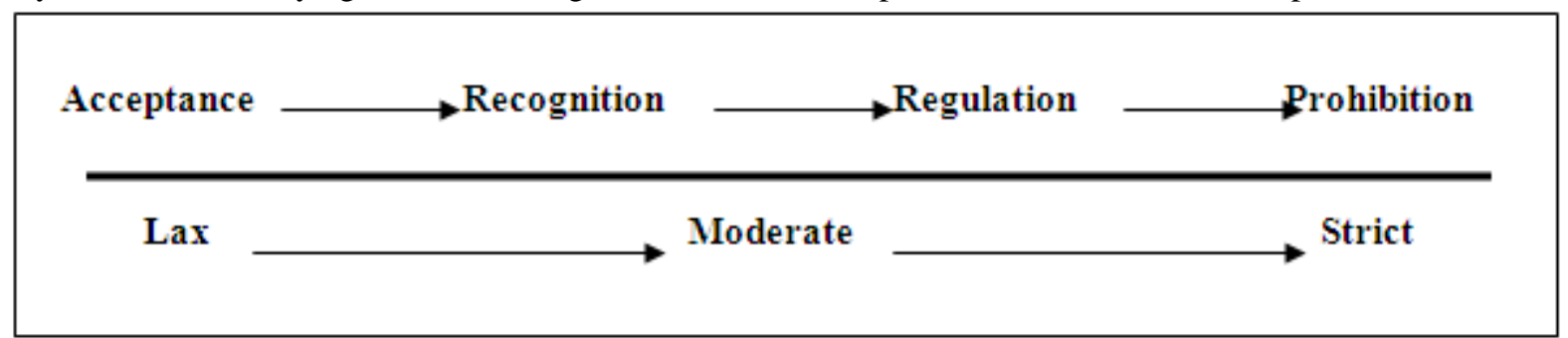

Figure 1: Spectrum of Public Policy Responses to Informal Public Transportation, Source: Cervero, R. Informal Transport in the Developing World, 2000.

Finding the right balance between private sector participation and public oversight in the light of the regulatory continuum is the biggest contemporary concern. Noteworthy is the fact that, acceptance, recognition and regulation have to varying degrees produced better results for developing nations, as against prohibition [12, 13]. This is mostly linked to the significantly weak capacity of regulators to plan and control public transportation service. The skeletal, if not nonexistent institutional and regulatory frameworks are usually blamed. However, the strong political and public influence informal public transport operators' enjoy are other relevant factors of strength on their side. In fact, the drift is now towards explicitly minimizing conflict with informal transport operators, whilst empowering the state as regulator and planner [14]. For the operators, their most tolerable stance is for governments to put up with the sector.

Often, authorities believe that informal transport's costs to the city exceed benefits. Informally supplied small vehicle paratransit is typically viewed as part of the problem and not part of the solution [15]. The sector is usually not considered desirable by decision-takers, planners, and in some cases, even their customer base [4]. Thus decisions to ban or eliminate the sector can be somewhat impulsive and unanimous. Growing evidences against eradicative policy measures like prohibition has shown that it is not always in the greater public interest $[16,6,3]$. Poor understanding of the benefits and costs of informal transport by some local authorities, particularly in the poorest parts of the world, make them simply give up on the sector, "content to let it exist on the margins of society [2]". Therefore, city authorities of developing nations often ignore the sector in terms of policy making [12]. A host of research works have argued that decisions as to whether to integrate, transform, replace, or eliminate the sector are based mainly on issues of environmental friendliness, disorderliness, public safety and most of all government policy mind set $[2,4]$. Not necessarily weighed against the socio - economic and mobility benefits the sector engenders.

Other arguments about the negative survival and market share protection antics of informal transport operators have indicted the sector as a cause of traffic congestion, accidents, air and noise pollution [17], 
justifying the stance of city authorities to prohibit. The apparent over-competition among operators has been noted to jeopardize safety of passengers, pedestrians and road furniture [18]. Fierce and intense competition among operators, sometimes lead to loss of lives, property and in some cases public disturbances $[8,19]$. Because revenues are wholly dependent on ridership, operators are pushed to fight for waiting passengers at bus stops and in terminals, this make driving becomes aggressive and dangerous, causing additional congestion and safety problems. Cream skimming acts of operators lead to operating only during profitable hours or at busy locations, and subsequent avoidance of low demand routes [7]. The apparent weak managerial capacity of operators, even when organized, also bothers policy makers and regulatory agencies.

Furthermore, it appears most authorities of informal transport dependent cities tacitly avoid dealing with route associations which often times operate as oppressive cartels. These groups usually fix prices and determine service practices. Policy makers and regulatory agencies tend to be wary of the ability of the informal transport sector to put up strong opposition to new initiatives [20]. The sector's entrepreneurial drive makes it typically averse to any effort to restrict or regulate [21]. Commentators have repeatedly pointed out issues of labor abuses, manifesting in the form of disregard for laws related to minimum salaries, workers' age limits, and work-hour restrictions $[2,8,1]$. As a result, even users are at the receiving end due to ineffective and weak regulatory ability of concerned agencies. This usually leaves passengers no avenue for complaints about service [8]. These kinds of situation underscore the need for government participation in paratransit operation, if only to protect the users, who are citizens with basic rights accruing to them.

The informal transport sector has been noted to rarely transform into corporate forms [12]. It thrives on the entrepreneurial spirit of thousands of individuals who each own small numbers of vehicles. A fundamental consequence is that these players are focused on their individual advantage, unlike corporate operators who seek to optimize resources and inputs. Therefore, convincing the operators to cooperate in an inclusive framework could be an uphill task. This is tied strongly to the atomized nature of ownership and horizontal integration between operators [2]. Furthermore, the mistrust of government, limited understanding of the economic benefits of coming together and strong emotional ties to existing business frameworks [22], compounds the situation. In management terms, concerns has been about the apparent lack of know how to control costs, expenditures and revenues, which further threatens the long-term financial health of informal transport businesses. Affirmation that many operators in the informal transport sector lack the most basic accounting practices, is shown in [8]. Consequently re - investment in new stocks and upholding of good maintenance practices becomes difficult, leading to low margins of profitability. Absence of vehicle or passenger insurance and other legal back up documents represents some of the reasons why conventional banks and other financial institutions shy away from dealing with informal transport operators.

A consensual stance is also evident in the literature as pointed out in [2], that the sector has emerged due to major gaps or failures in the transportation market. Hence, [23] advised that transferring mobility concepts to other settings, must involve understanding the dynamics of participation within the sector. The extent to which the informal sector is a product of the environment in which it has emerged must be understood. Adding that, identifying attributes that would be different and intrinsic to paratransit in particular cities is paramount. Another point of convergence is that paratransit operations usually originate from unauthorized or even illegal operations. So, unless regulatory frameworks evolve to recognize and accept paratransit services, they will remain exclusively outside acceptable mobility options. Thus, establishing the right kind of approach that would create wider common grounds, not only recognized by operators, but which lends itself to sustainable implementation, are key factors that should continue to underscore arguments about the recognition and inclusion of the informal public transport sector as part of mobility solutions in developing nations in the meantime.

\section{Lessons from Informal Transport Formalization and Regulation Assessment Efforts}

From the many different arguments, several important issues can be deduced, some of which points to no go areas and others to possible strong indicators that can be leveraged towards a more effective management of paratransit sectors of informal transport dependent cities. These include;

i. Unregulated and unsupervised informal transportation will produce unwanted outcomes - therefore some degree of regulation is required, especially in low income - high unemployment environments.

ii. Reliance on operator cooperatives as instruments of organization and self - regulation can only yield minimal control, in ways wanted by the controlling cadre.

iii. The controlling cadre orchestrates resistance to new initiative mainly as a self preservation tactic not usually for sector development. The manifest horizontal integration and fragmented ownership structure attest to this.

iv. Informal modes can synergistically reinforce formal transportation, if properly, managed and integrated.

v. It is possible to systematically organize the informal sector when what to manage and how to manage are identified. 
vi. It is also evident that weak institutional capacity usually leads to undersupply of formal transit services, which in turn need to be heavily subsidized, even though mobility inefficiencies usually results in such scenarios.

vii. The management capacity of both public regulators and informal transport operators need to improve.

viii. Services provided by the informal transport sector must transform to something users voluntarily choose.

ix. The loose internal organizational structure and weak operator to operator interaction offer regulatory opportunities and advantages towards implementing reforms.

x. The benefits of the sector such as the organizational capacity, the ability to provide responsive services regardless of the unfavourable environment are advantages that must be sustained.

xi. Small capacity vehicles can service large market shares owing to ability to effectively respond and adapt to changing situations.

xii. Technological developments such as Intelligent Transport Systems can enable more beneficial outcomes in the regulation and enforcement of minimum management and operational standards.

xiii. Most scholars agree that appropriate frameworks are needed to transform the sector, since existing frameworks either do not recognize informal public transportation or are hostile to it. Ways and means of exploiting inherent advantages of the sector need to be developed.

xiv. The pervasive negative perception of informal transportation is reducing, as many "for" arguments are now being raised. Though this is true for the research realm, policy makers and regulators still require a good measure of convincing. As a matter of priority the policy mindset that excludes the informal transport sector as a viable mobility option needs to change among decision makers.

\section{Framework Development Considerations}

A number of traits can be deduced from nuances in the underlying arguments on paratransit regulation and formalization that could be synthesized or used to develop useful criteria for paratransit operation management in developing countries. It appears that what is needed is to garner and harness the strengths of the sector while also identifying policy targets that will not "rock- the -boat". To do this, the major obstacle, that is, policy mind set must first change, then other points to capture based on lessons drawn from literature include;

i. Improved vertical and horizontal information flow within and between the regulators and the regulated.

ii. Seamless inter-agency cooperation and information sharing.

iii. Existing institutional capacities should form the bedrock of implementation strategies. Incremental changes can be imbibed on an "as needed basis".

iv. Promotion of operational independence for individuals or groups, within clearly defined guidelines.

v. Enlightenment towards awareness on advantages of economic aggregation and cooperation.

vi. Framework must be operator centered and bottom - up.

vii. Sanctions where avoidable should not target or impact income generation capabilities of operators.

viii. Need for technological aids towards improved monitoring.

ix. Authorities should aim to assist and guarantee operator finances, after due diligence.

$\mathbf{x}$. Reliable operator data capture and storage system required.

\section{The Framework}

From the foregoing, it appears as if policy mind set, inadequate information flow, self preservation and fragmentation are the key obstacles to harnessing opportunities inherent in informal public transportation. Therefore, a process designed to improve information flow between regulators, operators and users, may provide the building blocks for a more functional informal transport management framework for Nigeria. The main strength here is the feedback loops between operator, user and regulatory (institutional) attributes. The quasi - formal framework requirements are deduced from cross - examination, triangulation, and vertical and horizontal information synthesis. Any informal transport dependent city can use or adapt the schema, depicted as "Fig. 2" in the development of a management framework, considering the peculiarities of such a city. Essentially the contextualization and adaptation of global best practices and success factors to local situations, taking into consideration local transport policy, public transport regulations, and regulatory lessons from other cities with similar attributes, can help in the determination of appropriate regulatory and management disposition needed for local circumstances. Then, priorities, requirements, such as institutional needs, operational needs, management obligations, regulatory indicators and framework targets and prerequisites can be identified. 


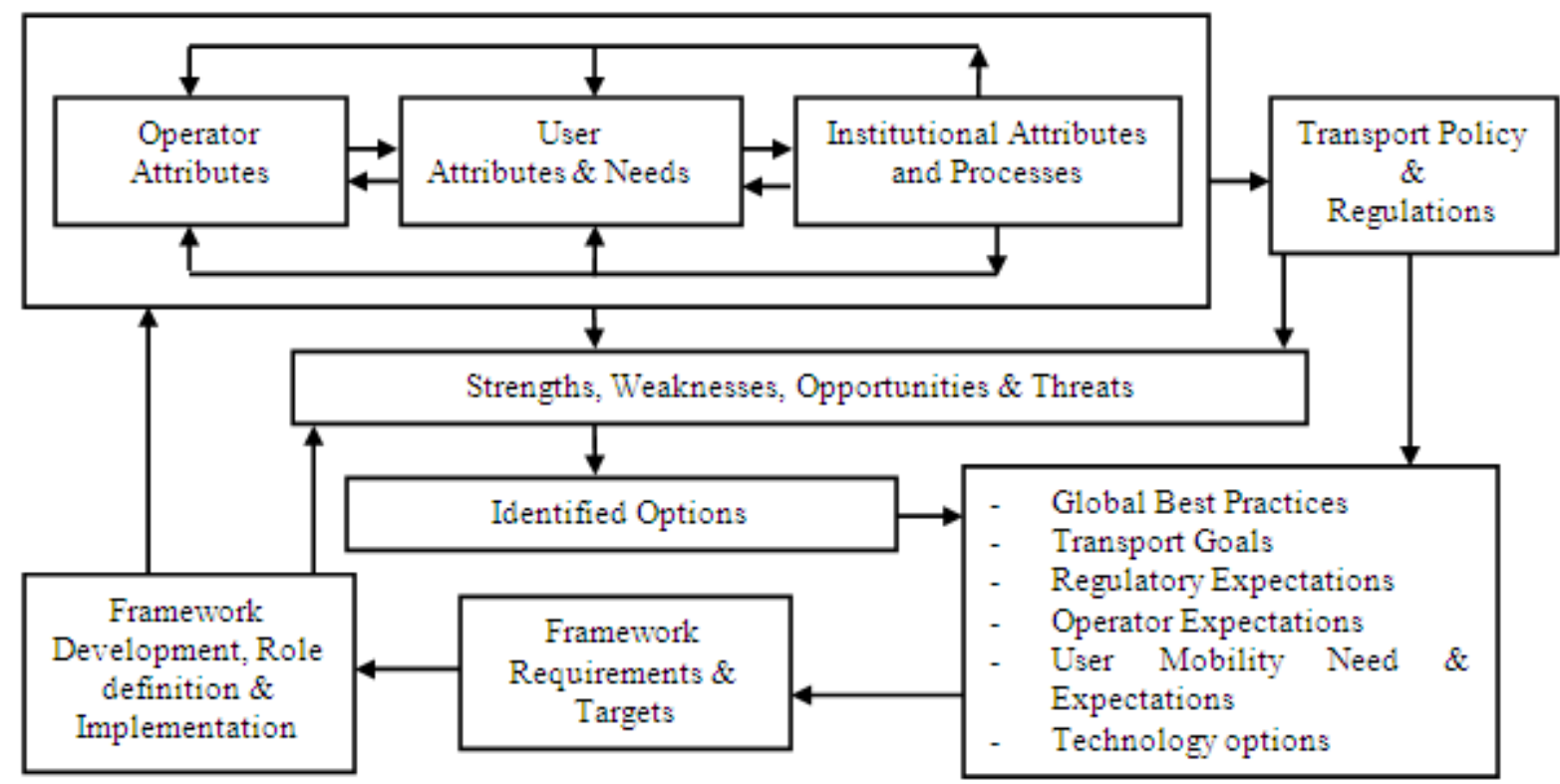

Figure 2: Framework for Quasi - Formal Management Approach to Paratransit Operations

\section{Conclusion}

The study advocates for a new approach to informal transportation regulation and seeks to bring about a better understanding of the advantages of people centered mobility solutions, most especially in environments where planning is still top- bottom. Policy shifts, especially in areas regarding urban transportation and general mobility provisioning are needed. Since, most of the indicting issues of the informal sector may turn out to be more manageable in future. Pollution control for instance, can be improved with the use of clean fuel, congestion mitigation may result from systematic deployment of vehicles via intelligent systems. Smart publicprivate partnerships can also lead to workable organizational and operational frameworks for public transportation in previously fully informal settings. Smartphone transport apps are increasingly becoming popular. Therefore congestion, pollution, and sector organization may not remain as big issues in future. However, unemployment and mobility challenges will still strongly feature in policy development circles. Moreover, efforts at characterizing and regulating the informal transportation sectors of various cities in different developing nations have yielded valuable insights as to how organizing the sector should proceed. The need to accept the informal transport sector as a complement of formal transportation has been raised. The systematic and holistic development of "fit for the situation" frameworks is very important, the need to involve operators in the development of necessary management and operational instruments is also imperative. The edge that can be brought to bear by technology in terms of operator registration and licensing, traffic management and transport service deployment have also been recognized as key factors to transforming the informal transport sector for optimal benefits. The tilt towards only regulatory frameworks must start to move towards including the operational aspect of informal transportation which perhaps might be the missing link. It is hoped that, the hitherto domineering use of economic, vehicle related and transport infrastructure development parameters to assess informal transportation will be relaxed to accommodate other dimensions of mobility requirements of a city. In order to support mobility planning and management with benefits for a wider spectrum of the society given identified peculiarities.

\section{References}

[1]. P. Wilkinson, Formalizing Paratransit Operations in African Cities: Constructing a research agenda. Proceedings of the 27 southern African Transport Conference, 2008, 480 - 490

[2]. R. Cervero, Informal Transport in the Developing World, United Nations Commission on Human Settlements, Nairobi, Kenya, 2000.

[3]. The PUNCH Newspapers, $17^{\text {th }}$ January, 2013, www.punchng.com

[4]. R. Cervero, and A. Golub, Informal transport: A global perspective. Transport Policy 14, 2007, 445-447.

[5]. UN-Habitat, Bridging the Urban Divide: State of the World's Cities 2010/2011, United Nations Commission on Human Settlements, 2010

[6]. B. Ibitoye, and A. Bello, Effects of Congestion and Travel Time Variability along Abuja - Keffi Corridor in Nigeria, Global Journal of Researches in Engineering.12(3), Version 1, 2012.

[7]. R. Otani, Menace of Deadly Matatus to be Cubed, African Business, Available from: http://www.africasia.comlicpubslab/sept99/abcf0903.htm, Retrieved 08/09/14. 
[8]. A. Golub, Welfare analysis of informal transit services in Brazil and effects of regulation, PhD Dissertation. Department of Civil and Environmental Engineering, University of California, Berkeley, 2003.

[9]. K. Adeniji, Transport challenges in Nigeria in the Next Two Decades, Monograph Ibadan: Nigerian Institute of Social and Economic Research (NISER), Transport Studies Unit, 2000.

[10]. M. Haider, and M. Badami, Public Transit for the Urban Poor in Pakistan: Balancing Efficiency and Equity. Regional Focus; New Delhi, India, 2004.

[11]. O. B. Olufemi, and M. S. Oluseyi, The Urban Poor and Mobility Stress in Nigeria; Environmental Research Journal 1(1 - 4): $1-8$, Medwell Online, 2007

[12]. P. Wilkinson, Incorporating informal operations in public transport system transformation: the case of Cape Town, South Africa; Brazilian Journal of Urban Management. 2(1), 2010, 85 - 95

[13]. J. Barrett, Organizing in the Informal Economy: A Case Study of the Minibus Taxi Industry in South Africa. International Labour Organisation, SEED Working Paper No. 39, 2008.

[14]. N. Kete, L. Schipper, L. Gutiérrez, R. Muñoz-Raskin, A. Lobo, and A. Baranda, A Case Study in Real Time: Mexico City BRT Metrobus, EMBARQ- World Resources Institute, 2005

[15]. World Bank, Urban Mobility: Profitability and financing of urban public transport microenterprises in Sub - Saharan Africa, an overview of the regional study conducted in Abidjan, Bamako, Harare and Nairobi. SSATP working paper No. 54, African Regional, 2001.

[16]. M. Engelskirchen, Sustainable Transport: A Source Book for Policy Makers in developing Cities. Available at: www.gtz.de/transport, 2011, Retrieved 11/09/14

[17]. T. Shimazaki, and M. Rahman, Operational Characteristics of Paratransit in Developing Countries of Asia. Transportation Research Record; 1503, 1995, 49-56.

[18]. A. O. Shittu, Exploring Pedestrian Challenges and Safety Experience along Samaru - Shika Transport Corridor in Zaria, Construction Focus, 2(2), 2013.

[19]. P. Anderson, Minibus Ride: A Journey through the Informal Sector of Kingston’ Mass Transportation System, Kingston Institute of Social and Economic Research, University of the West Indies, 1987.

[20]. X. Godard, Coping with paratransit in developing cities: a scheme of complementarity with institutional transport, Gothenberg, Sweden, Paper presented at Future Urban Transport Conference, Volvo Foundation for the Future of Urban Transport, April 2006.

[21]. X. Godard, and Ngabmen, H. (1998): Urban Transport in Sub-Saharan Africa, Habitat Debate, 4(2)15-16.

[22]. A. Lopez - Dodero, M. Casello, and A. Molinero, Private Bus Operators' Objectives in the Evaluation for Transit Investments in Developing Countries: A Conceptual Framework, 90th Annual Meeting of the Transportation Research Board. Washington, DC, 2011.

[23]. B. Finn, and C. Mulley, Development in market structure and regulation of urban bus services in developing countries and countries in transition. Journal of Public Transportation, 14(4), 2011. 